\title{
The Reclassification of Technological Knowledge Based on the Modularity Theory
}

\author{
Lin Runyan \\ School of Marxism, Zhaoqing University, Zhaoqing, China
}

Email address:

runyanlin@126.com

\section{To cite this article:}

Lin Runyan. The Reclassification of Technological Knowledge Based on the Modularity Theory. International Journal of Philosophy. Vol. 7, No. 2, 2019, pp. 87-92. doi: 10.11648/j.ijp.20190702.17

Received: May 22, 2019; Accepted: June 25, 2019; Published: July 10, 2019

\begin{abstract}
Technological knowledge refers to human body about design, manufacture and use of technological knowledge system needed for the Technological artifact. Carpenter, Ropohl, Vincenti, and Vries had classified the technological knowledge from different angles. With the development of technology, the content of the technological knowledge framework also continues to evolve, the classification of technological knowledge need to be reconsidered. From the perspective of modularity theory, the technological knowledge system can be decomposed into three main modules, and re-decompose the technological knowledge module into small modules. The dynamic integration between technological knowledge modules conducive to the flow of technological knowledge, and provide direct basis for further analysis and evaluation of technical education teaching.
\end{abstract}

Keywords: Definition of Technological Knowledge, Basic Characteristics of Technological Knowledge, Modular Classification of Technological Knowledge

\section{Introduction}

In the early stage, the research on technological knowledge is mostly about comparing and studying technological knowledge with scientific knowledge from the perspective of philosophy of science. However, since the unique dimension of technological epistemology is established, the internal logical structure and classification of technological knowledge are gradually revealed. After the empirical turn of technological philosophy, the essence of technological knowledge is revealed from the perspective of technological artefacts, and many technological knowledge classification frameworks are formed. With the innovation and progress of technology continuous developing, the range of technological artefacts is smaller and more complex, and the technological knowledge involved is more extensive. Therefore, it is necessary to discuss the classification of technological knowledge. Based on the modularization theory and the evolution of technology teaching content, the complex technological knowledge system can be decomposed into relatively independent and dynamically integrated into different knowledge modules, which is conducive to accelerating the flow of technological knowledge and developing a new way to construct the theoretical framework of technology education content.

\section{Content Definition of Technological Knowledge}

Plato proposed that "true belief justified" as the "standard definition" of knowledge, according to this definition, all classifications of technological knowledge cannot be accurately included. The analytical philosopher De. Vries also points out that Plato's definition of knowledge cann't be properly applied to technological knowledge, because it does not take the very important intentionality and normative nature of technological knowledge and how it fits into this proposition into account, nor does it justify all types of technological knowledge [1]. Carl Mitcham put forward the study of philosophy of technology through humanities tradition and engineering tradition. On this basis, technology is divided into four categories from the perspective of function: object, action, knowledge and will. Guolin $\mathrm{Wu}$ pointed out that technology comes from three elements: experience, entity and knowledge. Among them, the 
knowledge element is mainly composed of the technological knowledge, which is mainly derived from the technological rules, technological theories and scientific application [2]. Regarding technology as a kind of knowledge, which not only promotes the epistemological analysis of technology, but also transforms technology from an external extension of human beings into an internal component of thinking.

Aristotle used the example of a bed to distinguish between an artifact and a natural object. Science is concerned with natural things, while technology is concerned with artificial things, thus distinguishing technological knowledge from scientific knowledge. Some scholars respectively elaborated the definition of technological knowledge. For example, Layton pointed out that technological knowledge is about how to do and make things. Zhaoyou $\mathrm{Li}$ believes that technological knowledge is formed in the practical process of transformation and control of nature, and is manifested in the integration of technical principles, rules and skills [3]. In this paper, technological knowledge can be regarded as the knowledge system required for designing, transforming, or making and using technological artifacts.

\section{Review of Classification of Technological Knowledge}

\subsection{Carpenter-Mitcham's Classification Framework for the Technological Knowledge}

Carpenter proposed to divide technological knowledge into four frameworks: craftsman skills, technical aphorisms, descriptive laws and scientific theories [4]. Based on the acceptance of Carpenter's classification of technological knowledge into four categories, Mitcham changed scientific theory into technological theory. This also overlaps with the technology as knowledge proposed by Mitcham, which includes technological theory, technological principle, technological rules and other elements.

Craftsman skills are about automating the process of making and using artifacts. The acquisition of such technological knowledge requires intuitive training and repeated practice, just like that of traditional apprenticeship training. Rule of thumb is a simple empirical summary that has been developed over time and can be used in many situations. Descriptive law is based on specific experience, observation and description of object.

\subsection{The Classification of Technological Knowledge Based on Five Historical Events in the Field of Aviation}

From the perspective of historical facts of the aviation industry, Vincenti summarized and classified the technological knowledge involved in five cases of aviation history, including wing design, flight quality problems, control volume, propeller selection and riveting innovation.

Vincenti points out that engineering is a problem-solving activity, and engineers are a subclass of technicians. Vincenti focuses on the knowledge that engineers need in their day-to-day technical activities and experience. Furthermore, the technological knowledge is divided into six categories: basic design concepts, standards and specifications, theoretical tools, quantitative data, practical considerations and design tools [5]. These six types of technological knowledge are interlinked and reflected in the practice of technological conventional design. Basic design concept is also known as conventional design concept, including two aspects of operation principle and conventional configuration. When these two aspects change at the same time or one of them changes, the basic design will become unconventional design. Conventional design and unconventional design show that there is a hierarchy of technological design, while Vincenti focuses on the low-level design activities of conventional design. Conventional design concepts are materialized by engineers as specific artifacts that require design standards and detailed specifications, and the transformation from design specifications to quantitative indicators requires the designer to apply the scientific knowledge that has been extended and defined by practice as a theoretical tool. Once a theoretical tool is applied, it needs the assistance of various data, including descriptive data and prescriptive data. Vincenti also points out that there is a need to consider knowledge derived from practical activities, mostly non-coded tacit knowledge, to complete the design [6].

Vincenti pointed out that the above six types of technological knowledge are generated from the interaction of the seven activities of science conversion, theoretical engineering research, invention, experimental engineering research, production, design practice and daily operation [5]. Although Vincenti has identified the sources of engineering design knowledge after classifying it. However, Vincenti proposed that these six types of technological knowledge do not involve clear guiding principles, but are mostly personal reflections on aviation engineering historical case studies as design guiding principle [7]. Its classification system fails to establish a connection with the theory of action, and the classification of technological knowledge involved only solves the classification of design knowledge in the special field of aviation design knowledge.

\subsection{Ropohl Extended the Classification of Technological Knowledge}

G. Ropohl, a German philosopher of technology, philosophically classified technological knowledge in terms of what the technologist should know. Ropohl first summarized the characteristics of technological knowledge in engineering practice, and then extracted the technological knowledge needed by engineers to solve practical problems. On the basis of the above, five kinds of technological knowledge are put forward, which are the law of technology, functional rules, structural rules, technical know-how and socio-technical understanding [8].

Ropohl determined that the above five categories of technological knowledge are derived from the theory of technological systems. The law of technology is transformed from some natural rules about the process of technological 
activities. Most of the law of technology comes from the summary of experience, but not all of it comes from scientific theory. Even if it comes from the part of scientific theory, it needs the extension and running-in of technical practice. The practical object of engineers is the artificial object, and the structure and function are the dual nature of the artificial object. In order to achieve the predetermined goal in engineering design, in addition to the experience summary of technical rules and the interaction between structural rules and functional rules, practical reasoning is also needed to bridge the gap between function and structure, which requires technical know-how. Technical know-how is often uncoded, unspoken technological knowledge acquired through repeated practice. Engineering practices draw on many social contexts, such as the philosopher O. Y. Gasset said "I am me with my environment". Socio-technological understanding is a systematic knowledge of artificial objects, natural environment and social practice, and such kind technological knowledge is often a synthesis node of interdisciplinary knowledge [8].

Based on the classifications of technological knowledge of Carpenter, Mitcham and Vincenti, Rophol further developed the theoretical framework of technological knowledge classification. Compared with the former, Rophol's classification is more of a technological philosophy, and put forward "social-technical understanding" that the former lacks.

\subsection{De Vries Divided the Technological Knowledge in the Development of Technology into Four Categories}

De Vries divided the technological knowledge into four categories, the logic of entire classification process is rigorous, the internal connection strength is strong. De Vries took LOCOS as an example and put forward the technological knowledge involved in the development process of this local oxidation process technology. Therefore, technological knowledge can be divided into four categories: physical knowledge, functional knowledge, means-to-ends knowledge and action knowledge [9].

In this case, De Vries recognized that part of the knowledge derived from the functional observations of the membrane is related to the functional properties of the material. Taking Silicon Nitride as an example that impurities are not easy to invade at high temperature, it is shown that some knowledge is related to material properties and has nothing to do with scientific theories. "Mean-end" knowledge refers to the behavior required to achieve a predetermined goal, such as the fact that silicon nitride prevents the underlying silicon from being oxidized to achieve a function as a barrier film. Based on the consideration of the process of technological progress in the case, Vries mentioned the knowledge of taking corresponding actions to achieve a certain result, which can be called "action knowledge".

De Vries mentioned LOCOS as a case to study the classification of technological knowledge, the main purpose of which is to enrich Vincenti's empirical research of technological knowledge. According to Vries' analysis to further expand the four types of technological knowledge, physical knowledge is knowledge about artificial material physical nature, functional knowledge is knowledge about artificial object of intentionality, "Mean-end" knowledge is knowledge about some technological knowledge of the rules, action knowledge refers to the functional knowledge and production aspects. De Vries recognized that technological knowledge is the complex systems knowledge, contained in the process of designing, making and using technical objects [9]. The classification of complex technological knowledge is an important problem that technological knowledge theory should solve.

Comparing this four types of technological knowledge to Ropohl's and Vincenti's technological knowledge classification, can find that action knowledge just corresponding to Ropohl's function rule, Vincenti's theoretical tools, namely under certain environment to obtain the expected goal should be to take any action. Moreover, in the above classification of technological knowledge, Vries didn't distinguish ability and skill theoretically, nor did he lack the understanding of social technology.

\section{The Basic Characteristics of Technological Knowledge}

Before establishing the unique dimension of technology epistemology, technology is always regarded as the application of science. In this sense, technological knowledge is simply regarded as the application of scientific knowledge. Scientific knowledge is the pursuit of truth, emphasizing the interpretation of the world, which to some extent obscures the unique characteristics of technological knowledge itself. For scientific knowledge, we can simply summarize the truth, explanation, sharing, progress and other basic characteristics. The basic characteristics of technological knowledge can be summarized by investigating the types of above technological knowledge.

Philosophers such as Carpenter, Mitcham, Vincenti, Ropohl and Vries respectively analyzed and classified the content of technological knowledge from the perspectives of history, design and epistemology, as shown in the following table:

Table 1. Relevant scholars' classifications of technological knowledge.

\begin{tabular}{|c|c|c|c|c|c|c|}
\hline Scholars & Category1 & Category2 & Category3 & Category 4 & Category5 & Category6 \\
\hline Carpenter-Mitcham & The craftsman skills & rule of thumb & Descriptive law & Scientific theory & \multirow{4}{*}{$\begin{array}{l}\text { Practical } \\
\text { considerations } \\
\text { Social-technological } \\
\text { understanding }\end{array}$} & \multirow{4}{*}{$\begin{array}{l}\text { Design } \\
\text { tools }\end{array}$} \\
\hline Vincenti & Basic design concept & $\begin{array}{l}\text { Standards and } \\
\text { specifications }\end{array}$ & Theory tools & Quantitative data & & \\
\hline Ropohl & Technological rules & Functional rules & Structural rules & $\begin{array}{l}\text { Technological } \\
\text { know-how }\end{array}$ & & \\
\hline De Vries & Physical properties & $\begin{array}{l}\text { Functional } \\
\text { property }\end{array}$ & $\begin{array}{l}\text { Means - end } \\
\text { knowledge }\end{array}$ & Action knowledge & & \\
\hline
\end{tabular}


Scientific knowledge can be jusitified by true and false, while technological knowledge is judged by whether it is effective or not. Vincenti analyzed the associated knowledge of conventional design of technological artifacts. It can be seen from the analysis of the six kinds of technological knowledge that is necessarily related to practice or needs to be extended or expressed through practice. From the empirical turn of technology philosophy, the utility of technological knowledge can also be called practicality or action. If the application of technological knowledge can achieve the purpose of transforming and making artificial objects, it shows that technological knowledge is effective. The mean-end knowledge mentioned by De Vries also illustrates the utility of technological knowledge.

De Vries divided technological knowledge into four categories, among which action knowledge is with human purpose and intentionality. The purpose of applying technological knowledge is to transform or make artificial objects, or to integrate technological knowledge in the process of transforming or making artificial objects. Designing, manufacturing, using tools are all purposeful behaviors, and technological knowledge is the unity of cognition and intention.

Both the practical considerations mentioned by Vincenti and the technological know-how of Ropohl indicate that technological knowledge is indescribable. These can be called tacit technological knowledge which mainly based on practical experience, and also cannot be absolutely expressed. This kind knowledge exists in the minds of some people and can only be understood. As H. Dreyfus notes in his book "what computers can't do" that "what the masters really know is not in their textbooks". Just as Carpenter proposed craftsman skills, the tacit technological knowledge mainly based on practical experience is formed in technological practice, which needs to be acquired through continuous practice, and finally forms the execution automation of skills.

Technological practice is integrated with human's "purpose", and also the unity of cognition and intention, which makes the purpose become an inevitable factor of technological knowledge, reflected in the tacit nature of technological knowledge. The tacit nature of technological knowledge generally refers to the indescribable rules of technology, such as the descriptive rules first proposed by Carpenter and the technological rules later proposed by Ropohl. The experts work with tacit technological knowledge in the background, often without realizing they are using it. Since this kind of knowledge cannot be expressed in words, it can even be said that the engineer knows more than he realizes he knows, so this kind of knowledge can only be acquired and mastered through analogy or metaphor thinking and constant practice. For the mastery of tacit technological knowledge, it should be emphasized that the dynamic relationship between technological knowledge and situation, and the technological action also often depends on specific situation. So based on this, Ropohl supplemented the "social-technological understanding" knowledge on the basis of previous studies.

De Vries points out that the technological knowledge is included in the design, production and use of technology. Ropohl also thinks the function and structure rules are two kinds of important technological knowledge. Thus to explore the basic characteristics of technological knowledge, we need analyze structure and function as two properties. J. D. Ridder applied the functional decomposition and structural synthesis methods to analyze technological artifacts [10]. Decomposing the overall function of the technological artifact into a collection of sub-functions of lower order, and the functional decomposition process stops until atomic function appears. At this time, all atomic functions can be directly converted into atomic structures, which are then integrated into the component structures of technological artifacts until they are integrated into the overall structure [11]. The fact that technological artifacts can be decomposed and integrated shows that technological knowledge is also can be decomposed and integrated.

In conclusion, the basic characteristics of technological knowledge can be summarized into five aspects: effectiveness, intentionality, taciturnity, decomposition and integration.

\section{Reclassification of Technological Knowledge Based on Modularization Theory}

\subsection{The Connotation of Technological Knowledge Modular}

Modularity Theory was proposed by two professors Baldwin and Clark from Harvard University in their article "management in the age of Modularity" in 1997. They believed that Modularity Theory is one of the effective methods to organize and design complex products or processes. Modularity Theory means that the elements of the system can be separated and recombined [12]. The theory can be applied to different research fields, such as technology and management, biology, art design, artificial object design and manufacturing. Modularity Theory refers to the modularization of production process design in one way, in another way modularization refers to the dynamic process of module decomposition and integration with the system as the object. In the technological practice, the application of Modularity Theory is no longer limited to the traditional automobile industry, has been gradually applied to the design process of technological artifacts.

The basic condition of modularization theory is that objects are decomposable and integrable. Modularity simplifies complex systems. With the increasing complexity and uncertainty of product design, it is difficult to determine which technological knowledge can be used to solve practical problems even for technological artifacts in the same field. Most technological artifacts are designed, modified or made in the form of technological knowledge integration. In fact, 
the structure of technological artifact changes dynamically from integration to modularization and then to integration. It can be inferred from the above that the process of designing, transforming and making technological artifacts is also the process of modularizing technological knowledge.

\subsection{Modular Classification Process of Technological Knowledge}

De Vries pointed out that technological knowledge is included in the process of designing, making and using technological artifacts, and technological knowledge is an important teaching content of technological education. So exploring the process of designing, making and using technological artifacts is one of the main teaching tasks of technological education. The main content of technological education is to enable students to gain a deep understanding of the essence of artificial objects by discussing how to make artificial objects and analyzing their structure and function. Students conduct structured learning activities of "investigation, disassembly, installation, connection and evaluation of simple products" to help them gradually establish the thinking model of artificial structure-function, so as to successfully further transition to learning activities of "design and production ". Here, the teaching process of technological education can be summarized into three module stages: the teaching stage of designing knowledge, the teaching stage of transforming or making knowledge, and the teaching stage of using knowledge.

Based on the modularization theory and the changes of three stages in the process of technological education and teaching, the technological knowledge can be divided into three modules: design knowledge module, transformation or production knowledge module, operation and use knowledge module. Three technological knowledge modules interact with each other to form knowledge-based technology. Under human factors, they are materialized into new technological artifacts. The technological knowledge system contained in the new technological artifact is the result of the integration of the new technological knowledge and the existing technological knowledge, as well as the integration of the whole complex system of technological knowledge. The higher degree these three technological knowledge modules are dynamic integrated, the more conducive the technological artifact innovation is.

The three teaching stages of exploring how to make technological artifacts need to acquire design knowledge, transform knowledge, and use knowledge. The connotations of the three types of knowledge correspond to the quantitative data and practical considerations proposed by Vincenti, the functional knowledge, structural knowledge, society-technological knowledge, technological know-how, and technological laws proposed by Ropohl, and the instrument-objective knowledge proposed by De Vries. Based on this we can analysis the three technological knowledge module at the lower levels: knowledge module can be subdivided into functional knowledge, structure knowledge, quantitative data, material knowledge and social technological knowledge submodule. The transformation and production of technological knowledge module can be subdivided into tools - objective knowledge, manufacturing knowledge and know-how module. The operation and use of technological knowledge module can be subdivided into technological regulations and technological rules modules. The above technological knowledge modules and sub-modules are summarized in table 2:

Table 2. Technical knowledge module classification.

\begin{tabular}{llll}
\hline submodules & Design knowledge modules & Making knowledge modules & Operate and use knowledge modules \\
\hline Submodule11 & Functional knowledge & Means - end knowledge & Technological regulations \\
Submodule12 & The structure of knowledge & Manufacturing knowledge & Technological rules \\
Submodule13 & Quantitative data & Technological know-how & \\
Submodule14 & Knowledge of the material & & \\
Submodule15 & Social-technological knowledge & & \\
\hline
\end{tabular}

\section{Conclusion}

The reclassification of technological knowledge is based on the analysis of the existing classification of technological knowledge by Carpenter-Mitcham, Vincenti, Ropohl and De Vries. The basic characteristics of utility, intentionality, unspeakability, decomposition and integration of technical knowledge are investigated. These basic characteristics give technological knowledge the possibility of reclassification based on modularity theory. Technological knowledge can be divided into three categories: designing knowledge module, transforming or making knowledge module, operating or using knowledge module. These three technological knowledge modules interact with each other in an independent and dynamic way to promote technological knowledge to flow efficiently, and to enhance the competitiveness of core technologies [13]. With the empirical turn of philosophy of technology, the revelation of the essence of technological knowledge from the perspective of technological artifacts, and the formation of many classification frameworks of technological knowledge make the obscure content of technological education in the past gradually clear [14]. One of the essence of technological education is about technological artifacts. In the process of technological education, the structure and function of technological artifacts are analyzed to deepen students' essential understanding of technological artifacts [15]. Based on the learning of transforming or making technological knowledge modules, students can successfully further transition to the more open activities of "designing and making artificial objects" after the structured "structure-function" thinking model training. Based on the 
enlightenment of modularization theory, this paper discusses the possible approach to the reclassification of technological knowledge, and tries to complete the classification of modules and submodules of technological knowledge, so as to promote the development of technology epistemology and provide reference for the teaching design of technological education content.

\section{Acknowledgements}

The work described in this paper was fully supported by a grant from the "13th five-year plan"of Philosophy and Social Science Development Program of Guangzhou (No. 2017GZMZQN12).

\section{References}

[1] M. Vries, 'The Nature of Technological Knowledge: Extending Empirically Informed Studies into What Engineers Know' [J]. Techné, 2003 (6): 15-17.

[2] WU. Guolin, On the elements, complexity and essence of technology itself $[\mathrm{J}]$. Journal of hebei normal university (philosophy and social science edition) 2005, 28 (4): 91-96.

[3] Li. Zhaoyou, Song Baolin. On the generation and transformation of technological knowledge and its process essence -- from the perspective of technological innovation history [J]. Natural dialectics research, 2010, 26 (9): 24-28.

[4] S. R Carpenter. 'Modes of Knowing and Technological Action'[J]. Philosophy Today, 1974, 18 (2): 162-168.

[5] Vincenti, W. G. What Engineers Know and How They Know it: Analytical Studies from Aeronautical History [M]. Baltimore: Johns Hopkins University Press, 1990, 208-222.
[6] Zhang Huaxia, Zhang Zhilin. Research on technical interpretation [M]. Beijing: science press, 2005, 127.

[7] Houkes, W. 'The Nature of Technological Knowledge' [A], Meijers, A. Philosophy of Technology and Engineering Sciences [C], Amsterdam: Elsevier B. V., 2009, 323.

[8] Ropohl, G. 'Knowledge Types in Technology' [J]. International Journal of Technology and Design Education, 1997, 24 (7): 65-72.

[9] Meijers, A., Vries, M. 'Technological Knowledge'[A], Vincent F., Hendricks, A. Company to The Philosophy of Technology [C], Oxford: Blackwell Publishing Ltd, 2009, 15-17, 70.

[10] Pan Enrong. Engineering design philosophy -- the relationship between structure and function of technological artefacts [M]. Beijing: China social science press Club, 2011.

[11] Ridder, J. D. 'Reconstructing Design, Explaining Artifacts: Philosophical Reflections on The Design and Explanation of Technical Artifacts'[D]. Delft: Delft University of Technology, 2007, 82-129.

[12] Wikipedia. Modular theory [DB/OL]. https://en.wikipedia.org/wiki/Modularity2015 on September 7.

[13] Jinhan Park, Su Lee, Dilip Chhajed, and Kilsun Kim. 'Does modularizability of technology matter on the technology competition?'[J]. Asian Journal of Technology Innovation. 2018, 26 (1): 24-46.

[14] Mats Ahlskog, Jessica Bruch, and Mats Jackson. 'Knowledge integration in manufacturing technology development' [J]. Journal of Manufacturing Technology Management. 2017, 28 (8): 1035-1054.

[15] Matt Bower. 'Technology-mediated learning theory' [J]. British Journal of Educational Technology. 2019, 50 (3): 1035-1048. 